\title{
Medical Image of the Week: Coral Reef Aorta
}

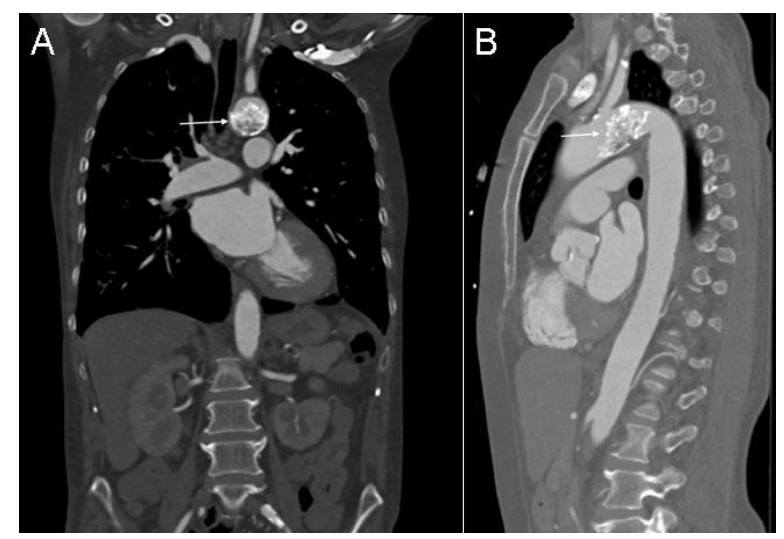

Figure 1. Coronal $(A)$ and lateral $(B)$ thoracic $C T$ in soft tissue windows showing the coral reef calcification (arrows).

A 52-year-old woman with no past medical history presented to the emergency department with signs and symptoms concerning for pneumonia. Chest x-ray showed incidental findings of a calcified aortic mass. Subsequently, a follow up computed tomography scan (CT) was obtained which showed coral reef aorta (Figure 1). On physical examination, vital signs were only significant for mildly elevated blood pressure to $146 / 62 \mathrm{mmHg}$. She also had normal and equal pulses and pressures throughout all 4 extremities. In retrospect, patient had complaints of bilateral lower extremity claudication on strenuous exercise.

Coral reef aorta, a rare condition that was first described in 1984 by Qvarfordt et al. (1) is characterized by an eccentric, heavily calcified polypoid lesion and stenosis of the juxtarenal and suprarenal aorta. The rock-hard, irregular, gritty, whitish surface of the calcification strongly resembled a coral reef. The most common presentation is severe hypertension and intermittent claudication. Magnetic resonance angiogram (MRA) and CT have the ability to diagnose and appreciate the extent of this phenomenon (2).

Lance Eberson $\mathrm{MS}^{1}$ and Sehem Ghazala MD²

${ }^{1}$ College of Medicine and ${ }^{2}$ Department of Internal Medicine University of Arizona

Tucson, Arizona, USA

\section{References}

1. Qvarfordt PG, Reilly LM, Sedwitz MM, Ehrenfeld WK, Stoney RJ. "Coral reef" atherosclerosis of the suprarenal aorta: a unique clinical entity. J Vasc Surg. 1984 Nov;1(6):903-9. [CrossRef] [PubMed]

2. Kopani K, Liao S, Shaffer K. The Coral Reef Aorta: Diagnosis and Treatment Following CT. Radiol Case Rep. 2016 Oct 4;4(1):209. eCollection 2009. [CrossRef] [PubMed] 